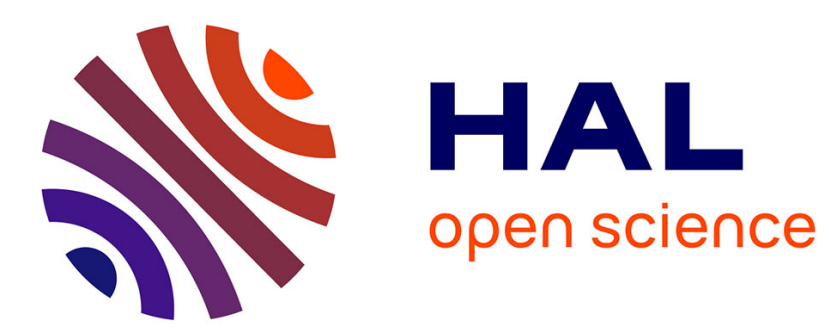

\title{
A TUNABLE, SHORT (5cm) GLASS FIBER LASER FOR HELIUM OPTICAL PUMPING
}

\author{
L. Schearer, P. Tin, E. Stephens
}

\section{To cite this version:}

L. Schearer, P. Tin, E. Stephens. A TUNABLE, SHORT $(5 \mathrm{~cm})$ GLASS FIBER LASER FOR HELIUM OPTICAL PUMPING. Journal de Physique IV Proceedings, 1991, 01 (C7), pp.C7-327-C7-330. 10.1051/jp4:1991787 . jpa-00251030

\section{HAL Id: jpa-00251030 https://hal.science/jpa-00251030}

Submitted on 1 Jan 1991

HAL is a multi-disciplinary open access archive for the deposit and dissemination of scientific research documents, whether they are published or not. The documents may come from teaching and research institutions in France or abroad, or from public or private research centers.
L'archive ouverte pluridisciplinaire HAL, est destinée au dépôt et à la diffusion de documents scientifiques de niveau recherche, publiés ou non, émanant des établissements d'enseignement et de recherche français ou étrangers, des laboratoires publics ou privés. 
JOURNAL DE PHYSIQUE IV

Colloque C7, supplément au Journal de Physique III, Vol. 1, décembre 1991

C $7-327$

\title{
A TUNABLE, SHORT (5cm) GLASS FIBER LASER FOR HELIUM OPTICAL PUMPING
}

\author{
L.D. SCHEARER, P. TIN and E. STEPHENS
}

Physics Dept., University of Missouri-Rolla, Rolla, MO 65401, USA

\begin{abstract}
The properties of a diode pumped, Nd-doped, tunable, short fiber laser are experimentally investigated. The laser is used to optically pump the metastable states of ${ }^{4} \mathrm{He}$ at wavelengths $1082.908 \mathrm{~nm}, 1083.025 \mathrm{~nm}$, and $1083.034 \mathrm{~nm}$.
\end{abstract}

CW and pulsed fiber lasers, made by doping rare-earth ions into monomode silica glass fibers, have important applications in optical sensors and communications. The small diameter of the fiber cores allow for good thermal conduction, low lasing thresholds and high gains.

In the end-pumped configuration, the lengths of the fibers are typically made greater than a meter in order to obtain sufficient absorption of the pumping source. The long length of these fibers does not preserve polarization, so that the output is, in general, elliptically polarized (1). This phenomenon presents problems when polarization dependent tuning elements are used inside the laser cavity because additional elements must also be installed to control the polarization. The insertion of these additional elements greatly reduces the power output of the laser.

The doping concentration of $\mathrm{Nd}^{+3}$ in these glass fiber lasers is typically $300 \mathrm{ppm}$. If additional impurities are added to the glass, concentrations up to several percent can be obtained. our search for an inexpensive, efficient laser source for optical pumping of the helium metastable states around $1080 \mathrm{~nm}$ led us to investigate a Nd-doped, diode pumped, tunable, short fiber laser which we report in this paper.

our fibers were grown for us, according to our specifications, by the Polaroid corporation. The fibers were approximately $5 \mathrm{~cm}$ in length and the cores contained around $2.5 \%$ Nd concentration by weight. The Nd-doped cores were 3 microns in diameter surrounded by a $\mathrm{SiO}_{2}$ glass cladding to bring the total fiber diameter to about $3 \mathrm{~mm}$. The indexes of refraction were such that the numerical apertures of the fibers were between 0.12 and 0.16 . The fibers were ground and polished at both ends and the input end of the fibers were coated to give a high reflectivity (>95\%) at 1.06 microns and a high transmission (>80\%) at $800 \mathrm{~nm}$. The output end of the rods were coated for high transmission $(>99 \%$ ) for $1060 \mathrm{~nm}$.

The basic fiber laser design is shown in figure (1). The pump source consisted of a laser diode (SHARP LT016MDO) with an aspheric collimating lensf $(f l=3.9 \mathrm{~mm})$. The diode is a single element, $40 \mathrm{~mW}$, 
$1 \times 4$ micron junction, laser operating at around $800 \mathrm{~nm}$. The collimated diode light impinges upon a negative steering lens ( $f 1=-150 \mathrm{~mm}$ ) and then upon a positive lens $(f l=4.5 \mathrm{~mm})$ where it is focused on the rod core. We found the steering lens very helpful, if not imperative, in efficiently coupling the pump light to the fiber core. Light emerging from the output end of the fiber is collimated by positive lens (fl=3.9 mm). A $6 \mathrm{~mm}$ thick Lyot filter and etalon 1 inserted for tuning purposes. Various output couplers complete the wavicy.

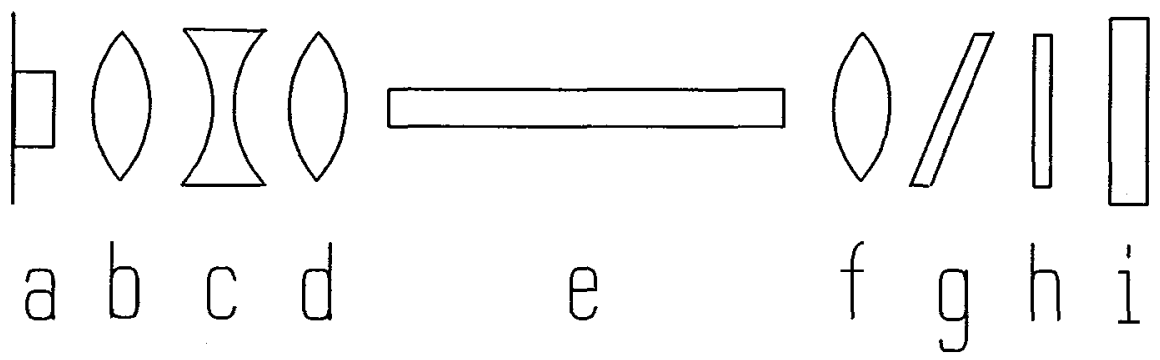

Figure 1. Fiber laser design: (a) diode laser pumping source, (b) diode laser collimating lens, (c) steering lens, (d) focusing lens, (e) Nd-doped fiber, (f) collimating lens, (g) Lyot filter, (h) etalon, (i) output mirror.

The fluorescence spectrum of the Nd-doped fiber was obtained by collimating the output from the core and projecting it into a Jarrel Ash $1 / 4 \mathrm{~m}$ monochrometer. The fluorescence spectrum of the fiber is illustrated in figure (2). This figure shows the peak fluorescence around $1060 \mathrm{~nm}$ due to ${ }^{4} \mathrm{~F}_{3 / 2}-{ }^{4} \mathrm{I}_{11 / 2}$ transitions.

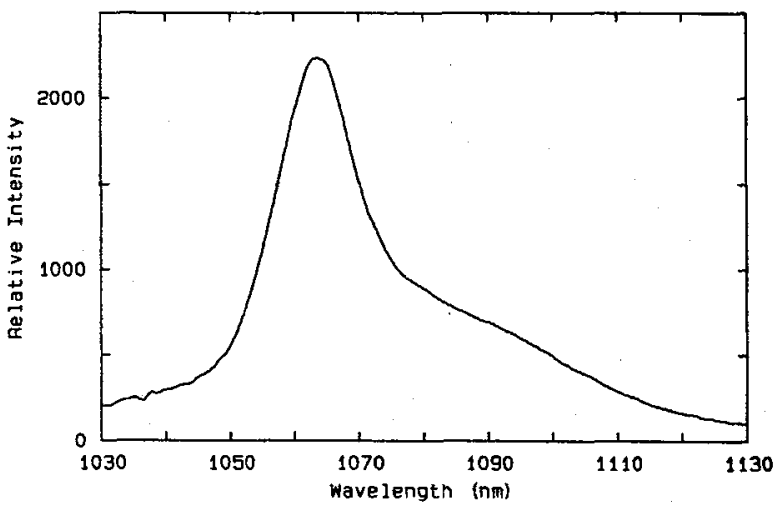

Figure 2. Fluorescence spectrum of $\mathrm{Nd}^{+3}$ in a glass fiber due to ${ }^{4} \mathrm{~F}_{3 / 2}{ }^{4} \mathrm{I}_{11 / 2}$ transitions.

The spectrum also shows substantial fluorescence occurs at $1083 \mathrm{~nm}$, suggesting that appropriate tuning elements within the cavity would permit lasing at the helium resonance transitions. The free-running fiber laser output as a function of wavelength is shown in figure (3). With an output coupler of $98 \%$ reflectivity approximately 50 microwatts of output power was obtained. 


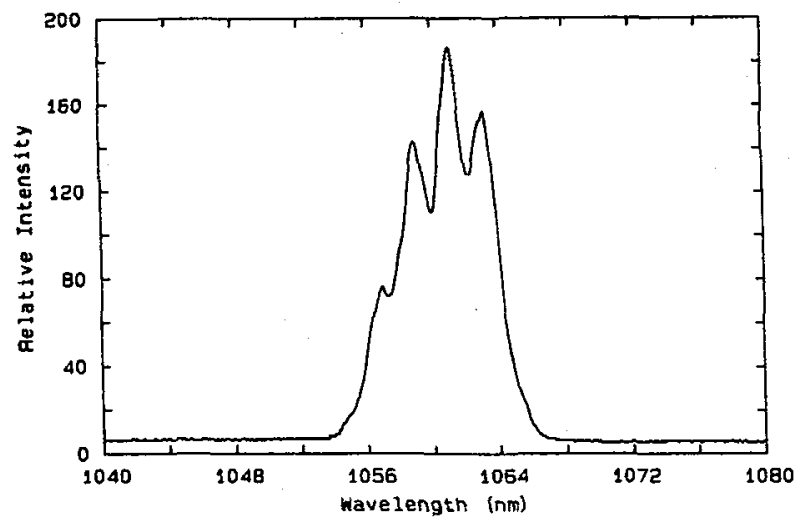

Figure 3. Spectrum of the Nd-doped fiber with a $98 \%$ reflection output mirror.

In order to tune the laser, a Lyot filter and a thin etalon ( $t=0.5$ $\mathrm{mm}$ ) were placed inside the cavity. With these elements we obtained the tuning curve shown in figure (4). The tuning range extended from 1054 $\mathrm{nm}$ to $1090 \mathrm{~nm}$ which includes wavelengths required for optical pumping the metastable states of ${ }^{4} \mathrm{He}$.

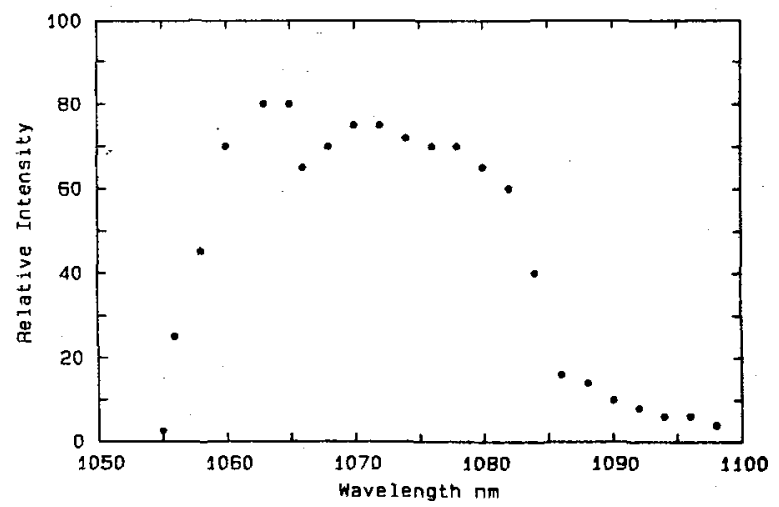

Figure 4. Tuning curve of the diode pumped Nd-doped glass fiber with $98 \%$ output mirror.

The addition of the etalon, which had a 50\% coating on each surface, to the cavity resulted in considerable narrowing of the laser line. The laser bandwidth is reduced to something less than the Doppler width of the helium metastable absorption lines (2). The fluorescence spectrum of ${ }^{4} \mathrm{He}$ obtained by frequency scanning the fiber laser is shown in figure (5). 


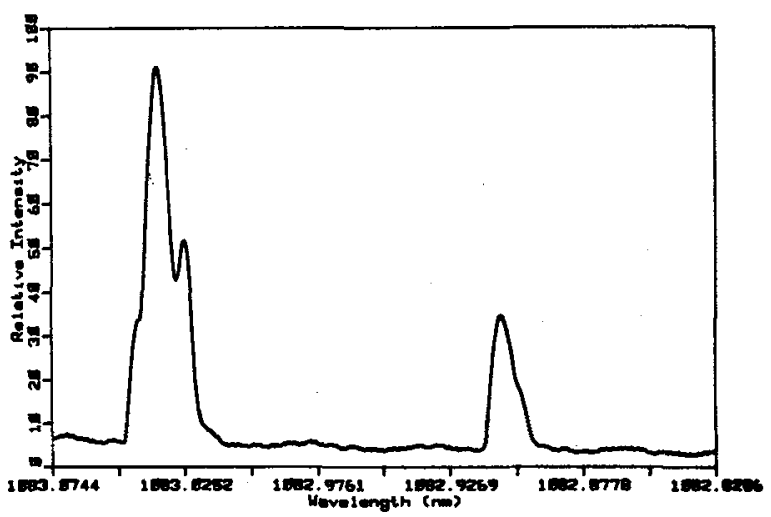

Figure 5. ${ }^{4} \mathrm{He}$ fluorescence spectrum obtained by frequency scanning the tunable Nd-doped glass fiber laser.

Power measurements where made using a calibrated silicon detector with a 1 micron high pass filter. The maximum power output from the fiber was obtained with a $95 \%$ output mirror. We obtained 75 microwatts output for 20 milliwatts pump power. We were unable to measure the pump power coupled into the cavity, nor could we reliably determine the amount of pump power absorbed by the fiber. slope efficiencies of approximately $29 \%$ for diode pumping of other fibers were reported earlier, suggesting that our system was inefficient in coupling the diode pump light into the fiber core.

In conclusion, we investigated the feasibility of using a diode pumped, Nd-doped, tunable, short fiber laser to optically pump ${ }^{4} \mathrm{He}$. We obtained free running output powers of around 100 microwatts and, with tuning elements inserted into the cavity, pumping the metastable states of ${ }^{4} \mathrm{He}$ at wavelengths of $1082.908 \mathrm{~nm}, 1083.025 \mathrm{~nm}$, and $1083.034 \mathrm{~nm}$ was demonstrated.

\section{References}

/1/ I. Alcock, A. Ferguson, D. Hanna, and A. Trooper, J. Opt. Soc. Am., 11 (11), 709-711 (1986)

/2/ E. Snitzer, Polaroid Corp., Cambridge, Massachusetts 02139 , private conversations. 